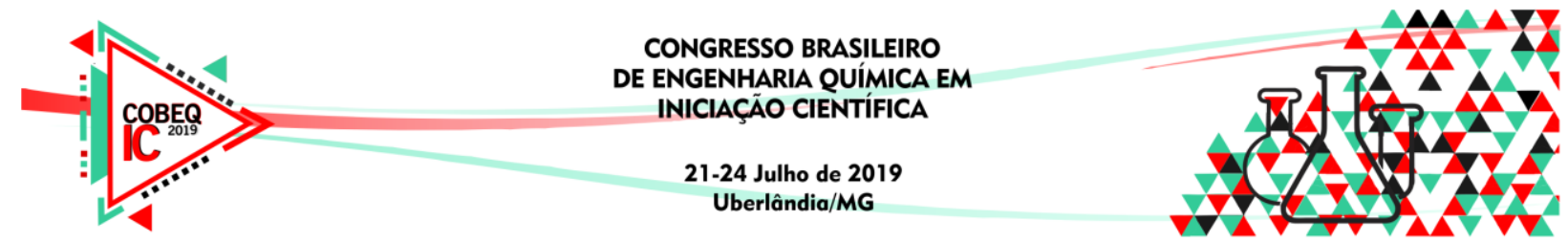

\title{
PURIFICAÇÃO DO BIODIESEL PELA ADSORÇÃO COM FÉCULA DE MANDIOCA
}

\author{
E. R. R. RODRIGUES ${ }^{1}$, M. B. P. O. SILVA ${ }^{1}$, G. S. S. ANDRADE ${ }^{1}$, L. LODI ${ }^{1}$ \\ ${ }^{1}$ Universidade Federal de Alfenas, Instituto de Ciência e Tecnologia \\ E-mail para contato: emillyrabelo5@gmail.com
}

\begin{abstract}
RESUMO - O biodiesel é um combustível proveniente de fontes renováveis, ao contrário dos derivados de petróleo. No entanto, o biocombustível deve passar por um processo de purificação antes de ser utilizado, já que a reação de transesterificação usada para produzi-lo possui glicerina como subproduto. A remoção da glicerina usualmente é feita por decantação seguida de lavagens com água, sendo utilizado um grande volume do solvente e gerada uma grande quantidade de efluentes para tratamento. $\mathrm{O}$ presente trabalho teve como objetivo estudar o método de purificação do biodiesel por adsorção com material sólido como uma alternativa ao uso de lavagens com água, com o objetivo de diminuir os custos do processo e o volume de efluentes para tratamento. $\mathrm{O}$ adsorvente utilizado foi a fécula de mandioca, um produto derivado de fonte renovável com produção nacional. Os resultados obtidos pela análise da amostra adsorvida possuem uma concentração de glicerina muito menor que a amostra que não sofreu adsorção, comprovando a eficácia do processo.
\end{abstract}

\section{INTRODUÇÃO}

De acordo com Dos Santos et al. (2014) combustíveis mais utilizados atualmente são obtidos de fontes não renováveis, como o petróleo. Sendo assim, fatores como a exploração descontrolada das reservas, o alto investimento necessário para prospecção em novas áreas, o consumo exacerbado e conflitos políticos existentes pelo seu monopólio causam uma grande oscilação de preços. Além disso, podem ser citados inúmeros impactos ambientais, como o agravamento do efeito estufa causado pela queima dos derivados de petróleo e consequente liberação do dióxido de carbono na atmosfera, o que torna cada vez mais importante a busca por outros tipos de combustíveis.

O biodiesel pode ser obtido através de matérias primas vegetais ou animais. Nos vegetais, são extraídos óleos de oleaginosas como soja, mamona, canola, dendê, girassol, pinhão mansão, amendoim e algodão, dentre outros. Já a matéria prima animal é sebo bovino, suíno e de aves, conforme definido pelo SEBRAE (2009).

Os trabalhos de Ramos et al. (2011) mostram que na primeira etapa da produção do biodiesel, ocorre a reação do metanol ou etanol com o óleo. A finalidade do processo de transesterificação é diminuir a viscosidade de óleo para seu uso como combustível. A proporção real seria de 3:1 (três mols de álcool para um mol de óleo), mas é mais conveniente utilizar 6:1 ou 12:1 para maximizar a produção de ésteres graxos. Para que o produto possa 


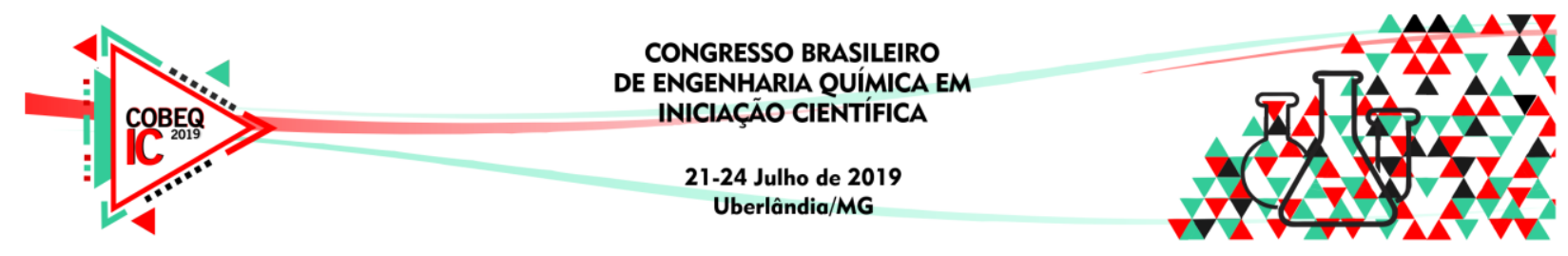

ser utilizado, de acordo com Da Silva et al. (2009) é necessária a retirada do excesso dos reagentes e do subproduto da reação, o glicerol. A separação da glicerina e outras impurezas é feita por decantação seguida de lavagem aquosa. Tal procedimento caracteriza-se por necessitar de grande quantidade de água.

A purificação por adsorção, por Vasques (2010), consiste em um processo por via seca com a vantagem de um menor volume de efluentes gerados. Como o processo de produção do biodiesel gera muitos resíduos, essa técnica se apresenta como uma boa alternativa para a diminuição dos contaminantes. Uma alternativa para a diminuição da quantidade de água gasta no processo é a substituição da lavagem por uma etapa de adsorção. O trabalho de Faccini (2008) mostra resultados positivos para o processo de purificação por via seca utilizando magnesol e sílica como asorventes. Uma outra alternativa ainda pouco explorada é o uso do polvilho, uma matéria prima totalmente brasileira, orgânica e barata que pode ser aplicada como adsorvente.

\section{MATERIAIS E MÉTODOS}

\subsection{Materiais}

Os materiais utilizados para a produção do biodiesel foram óleo de soja e metanol, e hidróxido de potássio como catalizador. $\mathrm{O}$ adsorvente utilizado foi o polvilho doce. Os demais reagentes foram empregados nas análises.

\subsection{Métodos}

Os procedimentos utilizados para as análises das amostras seguem a metodologia oficial do Instituto Adolfo Lutz (2008).

Produção do biodiesel: O biodiesel foi produzido por uma reação de transesterificação utilizando 500 gramas de óleo de soja e 109,9 gramas de metanol, obedecendo a proporção molar ideal de 1:6. O catalisador adotado foi o $\mathrm{KOH}$, e a quantidade utilizada foi de $1 \%$ da massa utilizada de óleo, o que equivale a 5 gramas. $\mathrm{O}$ processo ocorreu em um reator batelada.

Separação da glicerina: Como a obtenção do biodiesel gera subprodutos, foi realizada a decantação da mistura por um período de dois dias para uma primeira retirada da glicerina. Em seguida, foi feita a adsorção com o adsorvente polvilho doce em diferentes proporções, sob agitação constante por um período de 30 minutos. As quantidades de adsorvente utilizadas foram $1 \%, 2 \%$ e $3 \%$ da massa de biodiesel, sendo que a variação foi utilizada para encontrar o ponto ótimo do processo. O biodiesel foi deixado em repouso por 24 horas e filtrado para remover os resquícios de glicerina e do adsorvente.

Curva de calibração do glicerol: Para esta análise foram preparadas uma solução de acetilacetona $0,2 \mathrm{M}$, uma solução de metaperiodato $10 \mathrm{mM}$ e uma solução padrão de glicerol $0,036 \mathrm{mg} / \mathrm{ml}$. Para realizar a calibração da curva no espectrofotômetro, a solução de glicerol foi diluída em concentrações menores e analisada, possibilitando a construção do gráfico. Para a análise do glicerol presente nas amostras, foram usadas as mesmas soluções, 


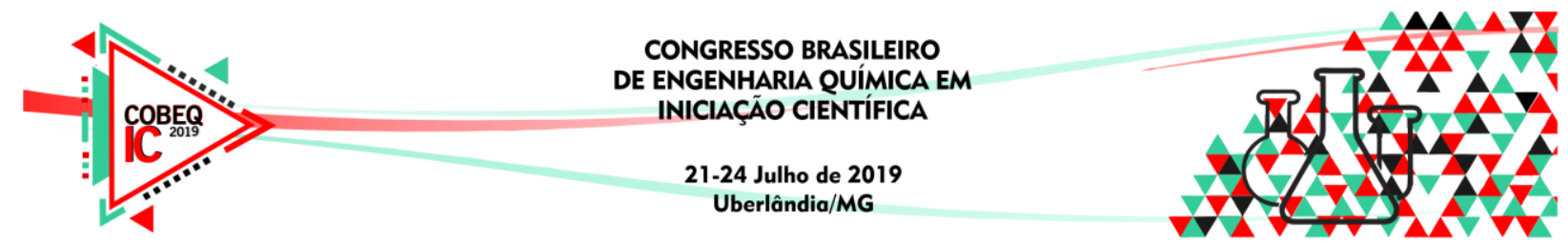

adicionando o biodiesel, e foi feita a análise no espectrofotômetro para o comprimento de onda de $410 \mathrm{~nm}$.

Teor de glicerina no biodiesel: Para avaliar o teor de glicerina no biodiesel produzido, $1 \mathrm{~g}$ de cada amostra foi colocado em diferentes tubos falcon, adicionados $4 \mathrm{ml}$ de hexano e $4 \mathrm{ml}$ da solução de etanol e água. Os tubos foram agitados em vortex por 5 minutos e colocados na centrífuga a $2000 \mathrm{rpm}$ por um período de 15 minutos. A fase superior foi removida e foram usados $0,5 \mathrm{ml}$ da fase inferior, $1,5 \mathrm{~mL}$ de solvente de trabalho, $1,2 \mathrm{~mL}$ de solução de $10 \mathrm{mM}$ de metaperiodato de sódio e 1,2 da solução de 0,2 $\mathrm{M}$ de acetilacetona em cada tubo de ensaio. $\mathrm{O}$ branco foi preparado com $2 \mathrm{~mL}$ de solvente de trabalho. Em seguidas as amostras foram aquecidas a $70^{\circ} \mathrm{C} 1$ minuto e resfriadas a $20^{\circ} \mathrm{C}$ por 2 minutos. Posteriormente foram realizadas as leituras das absorbâncias no espectrofotômetro no comprimento de onda de 410 nm e através da equação da reta obtida pela curva de calibração foi possível determinar a concentração de glicerol livre nas amostras.

Densidade: A densidade das amostras foi determinada utilizando a técnica de picnometria. Mediu-se a massa do picnômetro vazio e, em seguida, com água. Desta forma, utilizando a temperatura da água, foi encontrada a densidade referente e consequentemente o volume do picnômetro. O picnômetro foi limpo, seco, preenchido com biodiesel e pesado. Utilizando o volume encontrado previamente e a massa de biodiesel, foi possível determinar sua densidade.

Índice de acidez: Em um erlenmeyer de $125 \mathrm{~mL}$ foram adicionados $2 \mathrm{~g}$ da amostra e $30 \mathrm{~mL}$ de solução éter etílico e álcool etílico 1:1 (v/v). Em seguida, foram adicionadas algumas gotas de fenolftaleína. Procedeu-se a titulação com solução de $\mathrm{KOH}(0,01 \mathrm{M})$ até o surgimento da cor rosa persistente.

Viscosidade: A viscosidade dinâmica foi determinada utilizando um viscosímetro de Brookfield à temperatura de $40^{\circ} \mathrm{C}$. A viscosidade cinemática foi obtida pela razão entre a viscosidade dinâmica e a densidade das amostras.

Análise Cromatográfica: As amostras foram enviadas ao Laboratório de Análises de Combustíveis automotivos para que fosse analisada a concentração de glicerol no biodiesel sem adsorção e no biodiesel adsorvido.

\section{RESULTADOS E DISCUSSÕES}

\subsection{Curva de Calibração do Glicerol}

Os valores obtidos no espectrofotômetro para absorbância das soluções de glicerol em relação à concentração podem ser encontrados na Tabela 1.

Tabela 1: Dados de Concentração de Glicerol e Absorbância

\begin{tabular}{|c|c|c|}
\hline Volume (mL) & Concentração $\mathbf{( m g / m L )}$ & Absorbância $(\mathbf{n m})$ \\
\hline 0,1 & 0,00082 & 0,039 \\
\hline 0,2 & 0,00164 & 0,088 \\
\hline
\end{tabular}




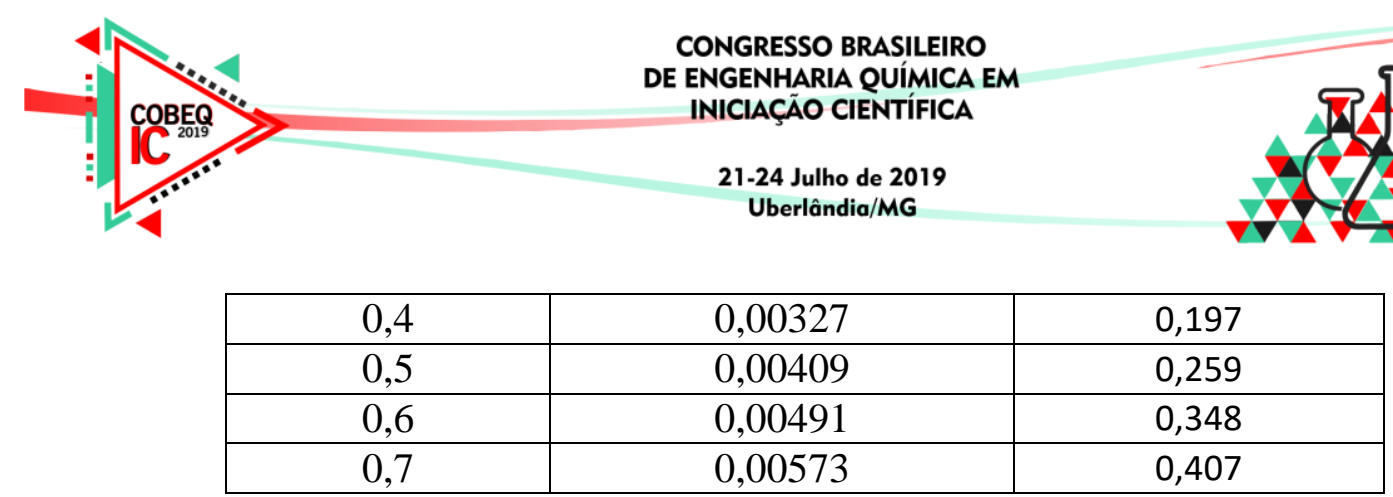

Através destes dados foi possível determinar a curva de calibração do glicerol, conforme mostra a Figura 1.

Figura 1: Curva de Calibração do Glicerol

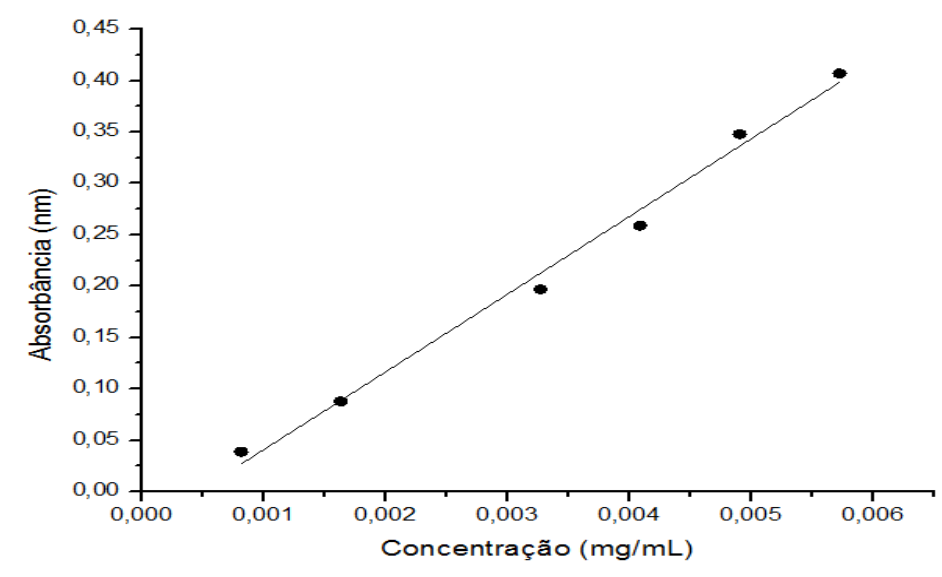

O valor do coeficiente de determinação obtido foi de 0,9919 , mostrando que os dados representam satisfatoriamente o comportamento da reta. A equação da reta (Equação 1) foi encontrada a partir do uso de planilhas eletrônicas, de modo que:

$$
y=75,611 x-0,0348
$$

na qual y corresponde à absorbância e x à concentração de glicerol, possibilitando quantificar o teor de glicerol nas amostras.

\subsection{Teor de Glicerol no Biodiesel}

Os valores obtidos para absorbância das amostras adsorvidas foram utilizados para determinar a concentração de glicerol equivalente nas amostras, utilizando a Equação 1. Os valores obtidos estão organizados na Tabela 2.

Tabela 2: Absorbância e concentração das amostras adsorvidas.

\begin{tabular}{|c|c|c|}
\hline Amostra & Absorbância (nm) & Concentração (mg/mL) \\
\hline Biodiesel Puro & 0,603 & 0,00844 \\
\hline Polvilho 1\% & 0,314 & 0,00461 \\
\hline Polvilho 2\% & 0,159 & 0,00256 \\
\hline Polvilho 3\% & 0,122 & 0,00207 \\
\hline
\end{tabular}




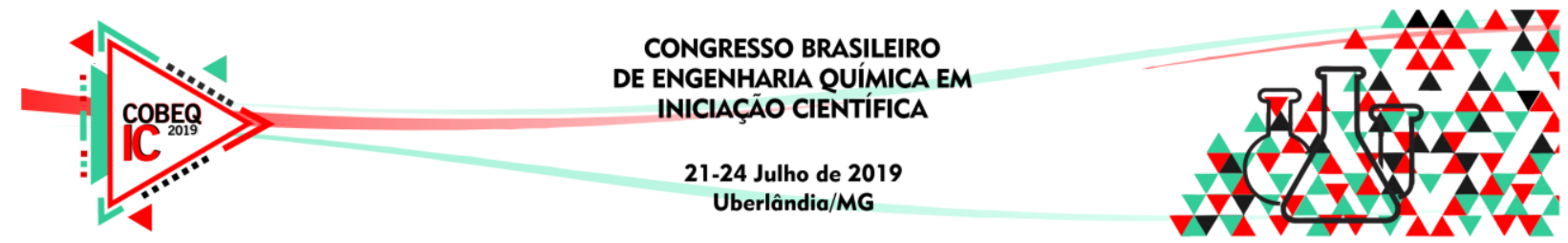

\subsection{Análises Físico-químicas}

A Tabela 3 relaciona os valores obtidos através das análises físico-químicas para o biodiesel puro e o biodiesel adsorvido com $3 \%$ em massa de polvilho doce, que foi a amostra com menor teor de glicerol entre as analisadas.

Tabela 3: Análise Físico-Química do Biodiesel.

\begin{tabular}{|c|c|c|}
\hline Análise & Biodiesel Puro & Biodiesel Adsorvido (3\%) \\
\hline Densidade a 20 $\mathbf{C ~}_{\left(\mathbf{K g} / \mathbf{m}^{\mathbf{3}}\right)}$ & 885,75 & 879,05 \\
\hline Viscosidade Dinâmica a 40 ${ }^{\circ} \mathbf{C} \mathbf{( c P )}$ & 4,20 & 4,44 \\
\hline Viscosidade cinemática $\left(\mathbf{m m}^{2} / \mathbf{s}\right)$ & 4,74 & 5,05 \\
\hline Índice de Acidez $(\mathbf{m g K O H} / \mathbf{g})$ & 0,1669 & 0,1666 \\
\hline Concentração de Glicerol livre $\mathbf{( m g / m L )}$ & 0,008 & 0,002 \\
\hline
\end{tabular}

As especificações da ANP (2014) limitam a densidade a $20^{\circ} \mathrm{C}$ do biodiesel entre 850 e $900 \mathrm{~kg} / \mathrm{m}^{3}$, de modo que as amostras se encontram dentro dos parâmetros.

Os valores de viscosidade cinemática a $40^{\circ} \mathrm{C}$ estão dentro do estipulado pela norma ANP que é de $3-6 \mathrm{~mm}^{2} / \mathrm{s}$.

O índice de acidez obtido foi de $0,1666 \mathrm{mg} \mathrm{KOH} / \mathrm{g}$ óleo, o que atende a especificação da Resolução ANP n 45 (2014), que estabelece que o limite máximo de acidez do biodiesel deve ser de $0,5 \mathrm{mg} \mathrm{KOH} / \mathrm{g}$ óleo.

A quantidade de glicerol livre na amostra adsorvida está dentro dos limites permitidos pela ANP, de no máximo $0,02 \%$ em massa.

\subsection{Análise cromatográfica}

Uma amostra de biodiesel antes da adsorção e uma amostra de biodiesel adsorvido com 3\% de polvilho foram analisadas por cromatografia pelo Laboratório de Análises de Combustíveis Automotivos (LACAUT).

As análises mostraram que na amostra sem adsorção o teor de glicerol livre foi de $0,13 \%$ em massa, enquanto no biodiesel adsorvido com $3 \%$ de polvilho doce em massa obteve um resultado menor que $0,005 \%$ em massa. Houve também uma redução no teor de glicerol total das amostras, que passou de $0,54 \%$ em massa no biodiesel puro para $0,48 \%$ em massa no biodiesel que sofreu adsorção.

Os resultados da análise comprovam que as quantidades de glicerol livre na amostra adsorvida foram sensivelmente reduzidas, assim como já era esperado pelos resultados da análise espectrofotométrica, mostrando que o processo de adsorção com fécula de mandioca para remoção do glicerol presente no biodiesel é eficaz. 


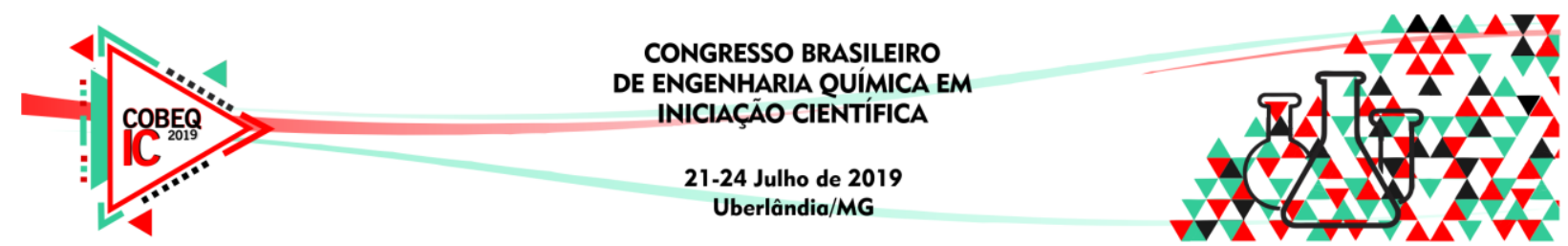

\section{CONCLUSÃO}

A partir da análise dos dados obtidos, é possível afirmar que o processo de adsorção do biodiesel utilizando fécula de mandioca foi bem sucedido, já que a concentração de glicerina é sensivelmente maior na amostra que não sofreu adsorção.

Além disso, as análises de viscosidade, índice de acidez, densidade e o teor de glicerol nas amostras para o biodiesel adsorvido estão dentro dos limites estabelecidos pela ANP, o que comprova que a reação de transesterificação foi bem sucedida e que o biodiesel possui as características necessárias para poder ser utilizado.

\section{REFERÊNCIAS}

ANP - Agência Nacional de Petróleo, Gás Natural e Biocombustíveis. Resolução $n^{\circ} 45$, de 25.8.2014 - DOU 26.8.2014.

DOS SANTOS, Silvio Francisco; BORSCHIVER, Suzana; DE SOUZA, Vanderléa. Mapping sustainable structural dimensions for managing the Brazilian biodiesel supply chain. Journal of technology management \& innovation, v. 9, n. 1, p. 27-43, 2014.

FACCINI, Candice Schmitt. Uso de adsorventes na purificação de biodiesel de óleo de soja. 2008.

INSTITUTO ADOLFO LUTZ. Métodos Físico-Químicos para análises de alimentos. São Paulo: Instituto Adolfo Lutz, 2008.

RAMOS, Luiz P. et al. Tecnologias de produção de biodiesel. Revista virtual de química, v. 3, n. 5 , p. 385-405, 2011.

SEBRAE. Biodiesel, Cartilha Biodiesel. Disponível em: <https://www.agencia.cnptia.embrapa.br/Repositorio/NT00035116_000gihb7tn102w x5ok05vadr1szzvy3n.pdf>. Acesso em: março de 2018.

SILVA, Gabriela Moraes et al. Avaliação da remoção do glicerol livre do biodiesel por adsorção. VIII Congresso Brasileiro de Engenharia Química em Iniciação Científica. Uberlândia. 2009.

VASQUES, Érika de Castro. Adsorção de glicerol, mono e diglicerídeos presentes no biodísel produzido a partir do óleo de soja. Curitiba. 2010 